\title{
Arquitectura mexicana en el siglo XIX. Cuatrocientos años de occidentalización
}

Carlos Lira

UAM-A

$\mathrm{E}$ 1 estudio general del siglo XIX en nuestro país, resulta mínimo si lo comparamos con el que se ha efectuado sobre los siglos coloniales. En el campo arquitectónico esta situación es aún más grave: si recurrimos a la bibliografía existente para el estudio de la arquitectura del $\mathbf{x I x}$, notaremos inmediatamente la diferencia, en número y aun en calidad, con la que existe para los anteriores siglos. A esta dificultad deberá añadirse la parcialidad, o más bien unilinealidad, de los juicios y conceptos con que suele calificarse aquella producción arquitectónica, surgidos exclusivamente a partir de los datos que la Real Academia de San Carlos aporta.
Respecto a la arquitectura del XIx, con frecuencia hemos oído afirmar, por ejemplo, que no hubo actividad constructiva abundante y de calidad por las guerras internas en las que se debatió el país; que la precaria economía no permitió un despliegue arquitectónico más amplio; que el control de la Real Academia no permitió, por su constante censura academicista, la construcción de innumerables proyectos y que incluso impidió un desarrollo estético más abierto, etc. Si bien todo esto es parcialmente cierto, no es suficiente para explicar el proceso arquitectónico que nuestro pais vivió para pasar de un explosivo barroco a un no menos explosivo eclec- 
ticismo porfiriano. Se habla demasiado del neoclásico en México, pero en realidad su estudio se limita a unas cuantas obras y a unos po$\cos$ arquitectos, algunos de los cuales, como Tolsá por ejemplo, que construyó buen número de las obras neoclásicas más connotadas, no era mexicano. Ante esto, creemos necesario acercarnos más profundamente a aquellos arquitectos reconocidos $o$ no por la Academia que no sólo con sus trabajos, sino aun con sus conceptos, hicieron obras neoclásicas en México desde su propia perspectiva "mexicana": pero igualmente nos inquieta abordar esa enorme etapa que va desde el florecimiento neoclásico hasta el porfirismo y que es simplemente saltada o sólo mencionada de paso, por la mayoría de los estudiosos del siglo XIX. ${ }^{1}$ Iturbide, Santa Anna y muy particularmente Maximiliano, crearon una brecha que preparó el camino al eclecticismo posterior. Pretendemos a futuro investigar este desarrollo arquitectónico. Por ahora plantearemos únicamente una serie de antecedentes de los cuales partiremos para, posteriormente, llevar a cabo la investigación.

Si bien la revolución industrial en nuestro país no se hizo totalmente

1 Podríamos comparar la actitud que muestra generalmente la historiografía arquitectónica con respecto al eclecticismo con aquella que menciona Andrés Lira en relación con la Reforma: "Debemos cuidarnos de incurrir -diceen un error común en la historiografía nacional: ver en la llamada Reforma [...] un hecho totalmente nuevo, aislado de sus antecedentes; pues sin reconsiderar éstos no comprenderemos la actitud de los habitantes de los pueblos." Comunidades, 1983, p. 286. evidente sino hasta el periodo porfiriano, una serie de fábricas y casas para obreros fueron la escasa muestra de los cambios que la sociedad de finales del XVII estaba comenzando a vivir. Mientras la revolución industrial, tanto en Europa como en Estados Unidos, modificaba profundamente la mentalidad y el ritmo de vida de sus habitantes e influía en adelantos técnico-constructivos, empleo de nuevos materiales y en la dinámica misma de la arquitectura, en nuestro país, ciertamente, no se pudo instituir tales modificaciones debido a la inestabilidad política, económica y social que vivía la emergente nación por aquellas décadas y que se prolongó durante todo el siglo XIX.

Bien escasa parece ser en la producción arquitectónica de México, durante los dos primeros tercios del XIX, la influencia de la revolución industrial. Así, en lo que se refiere al proceso de trabajo, por ejemplo, los cambios con respecto a la arquitectura colonial fueron prácticamente nulos: los materiales, sistemas y procedimientos constructivos, la fuerza y los medios de trabajo se mantuvieron casi constantes. Las relaciones y las formas sociales de producción, en cambio, se modificaron sustancialmente; ${ }^{2}$ las primeras avanzando hacia un capitalismo se aproximaron al proceso de manu. factura, trastocando la organización vigente durante los siglos barrocos; las segundas, fueron cambiadas notablemente a través de la Real Academia de San Carlos que intentó controlar, a partir de su fundación, las actividades

2 Lombardo de Ruiz, Ciudadela, 1980, p. 75. 
constructivas que se efectuaban en la capital y las provincias. Así, hacia 1808, se nombraron Académicos de Honor en Mérida, Veracruz, Guadalajara, Valladolid y Guanajuato para que controlaran la construcción en esos lu. gares. Cabe aclarar sin embargo, que en el caso de la organización gremial, también sabemos que en muchas provincias y pueblos ésta fue la que continuó rigiendo el trabajo; así,

el arraigo de las clases populares a la tradición gremial y religiosa del viejo régimen fungi6 como una capa impermeable que se defendió de la imposición de las imágenes extranjeras. ${ }^{3}$

Respecto al control ejercido por la academia, es aún más dificil comprobarlo, ya que incluso en la ciudad de México muchos maestros siguieron construyendo sin su permiso y supervisión. Más aún, con frecuencia pa. saron por alto su autoridad ya fuera usando artimañas diversas -como lo hiciera tantas veces Castera, de quien hablaremos más adelante- $O$ bien violando abiertamente las normas -como tan frecuentemente lo hizo Guerrero y Torres, cuya singular actitud suscitó en Sonia Lombardo el siguiente comentario-:

nunca cambió su estilo al clasicismo y, a pesar de que se le hizo maesto emérito de la academia, se opuso siempre a acatar las nuevas disposiciones y fungió con las reglas gremiales. ${ }^{4}$

3 Lombardo de Ruiz, "Reformas", 1986, p. 31. Ibid, p. 30.
Importa señalar aquí que el mismo Iturbide, al poco tiempo de ascender al trono imperial, $y$ ante la necesidad de hacer ciertas modificaciones al palacio, confirió el mando de las obras al obispo poblano Antonio Joaquín Pérez Martínez, destituyendo del cargo de maestro mayor de palacio nada menos que al arquitecto y profesor de la Academia de San Carlos, Joaquín Heredia. ${ }^{5}$ Años más tarde, en 1824, Vicente Guerrero contrató igualmente a pintores y arquitectos extranjeros, en vez de académicos, para nuevas obras en palacio.

Como mencionamos al inicio, muchos son los autores que sostienen que hubo una baja producción arquitectónica durante el xIx. La guerra de Independencia (1810), el primer imperio (1822), los diversos gobiernos constitucionales (1824-58), la guerra de Texas (1835), la guerra con Francia (1838), la guerra con Estados Unidos (1846), la guerra de los Tres Años (1858), la intervención francesa (1862), el segundo Imperio (1864-67), el gobierno juarista (1867) y el de Lerdo de Tejada (1872-76), fueron algunas de las etapas críticas que im. pidieron, efectivamente, la alta actividad constructiva que se había dado en otros tiempos. Si bien los conflictos mencionados arriba, así como el escaso crecimiento demográfico, "hicieron que la ciudad de México conservara hasta mediados del siglo XIX el perfil que se observa en los planos elaborados a fines del xvir", 6 los cam. bios en la ocupación de algunos terre-

5 Véase Acevedo, "1821-1843", p. 37.

6 Consúltese Morales, "Estructura", 1976, p. 364 . 
nos de la ciudad a raíz de la expulsión de los jesuitas (1767), la supresión papal de los antoninos (1787), así como la venta forzada de muchas fincas por la expedición de la Cédula de Consolidación de Vales Reales (1804) son fenómenos que, creemos, deben analizarse también para explicar globalmente el proceso arquitectónico del siglo XIX, al menos en la ciudad de México. La escasa actividad constructiva, como menciónamos,

da a los ojos de los historiadores el aspecto de un "periodo de estancamiento" en la expansión de la ciudad. Pero ese estancamiento $[\ldots]$ no puede interpretarse como una inmovilidad. No, porque en esa época se han ido gestando cambios que preparan la gran expansión material de ha ciudad que se da a partir de $1858 .^{7}$

Además de esto, las obras que generalmente se consignan son aquellas que por su monumentalidad, o por el apoyo oficial que recibieron saltan inmediatamente a la vista de los estudiosos, lo que deja fuera a obras menores y a proyectos no construidos que deben, creemos, incluirse para mayor objetividad. Por otra parte está la aplicación de la norma que pretende explicar el desarrollo arquitectónico en provincia, a partir de lo sucedido en la ciudad de México, situación que también nos parece equivocada. Sabemos también que se construyó mucho más de lo que se ha consignado; numerosos templos, teatros, mercados, mesones, edificios militares $y$ aun nuevos asentamientos

${ }^{7}$ Lira, Comunidades, 1983, p. 286 . en la frontera norte como el pueblo de Nuestra Señora de la Candelaria de Azanza, en el actual estado de Nuevo León, así lo demuestran. ${ }^{8}$ Proyectos tales como los arcos de acceso a la Alameda de Querétaro, la casa mesón con temazcal en Tacubaya, el templo del Señor Crucificado de Otatitlán, los diseños anónimos de algunos arcos triunfales para el recibimiento de Carlota y Maximiliano, así como las numerosas obras y proyectos arquitectónicos y urbanísticos realizados durante su imperio -que por cierto muchos fueron retomados y realizados en el porfiriato- son tan sólo el tímido indicio de una vasta producción que, al parecer, no ha sido estudiada y que impide, si no se incluye en los estudios arquitectónicos, un conocimiento más real de la arquitectura decimonónica. ${ }^{9}$

Debido a que los esquemas arquitectónicos neoclásicos fueron empleados en su mayoría para construir una serie de edificios representativos, primero del gobierno colonial y posteriormente del gobierno oficial en turno, liberal o conservador, el neoclásico fue considerado como un estilo "oficial", por lo que es muy posible que esto haya contribuido a hacerlo menos estimado por el común de la sociedad y por tanto que su arraigo fuera escaso dentro del gusto popular, evitando incluso que se propagara hacia los diversos territorios de la nueva nación. ${ }^{10}$ Tan ajeno debió pa-

B Este proyecto de Juan Crousel pucde consultarse en el Archivo General de la Nación (AGN), Tierras, vol. 3519, exp. 5, f. 8 b.

9 Todos los proyectos y expedientes de las obras citadas los hemos localizado en diferentes ramos del AGN.

${ }^{10} \mathrm{Si}$ bien es cierto que la arquitectura 


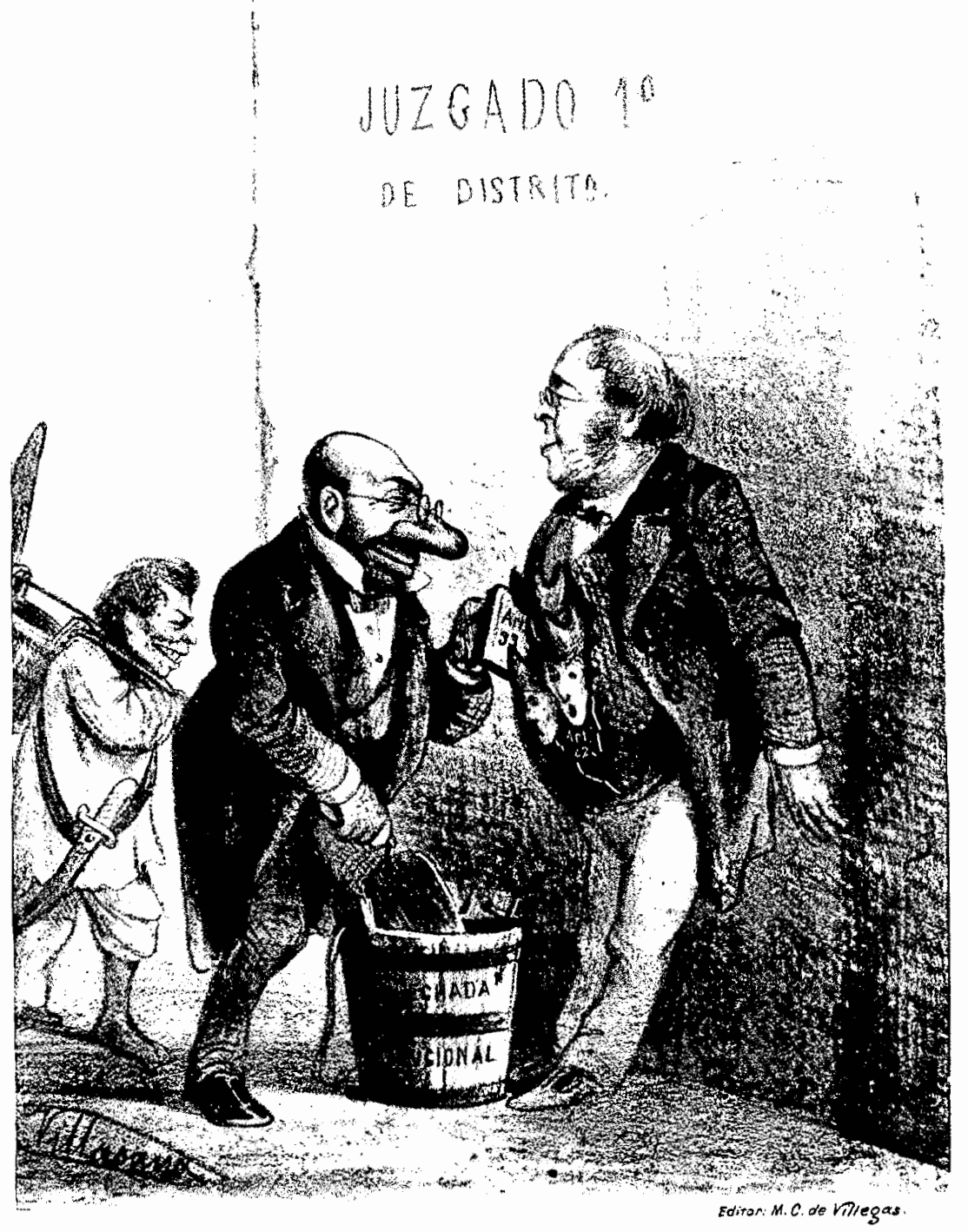


recer el neoclásico a la población, que ésta no parece haberse aficionado a él pese a las manifiestas ventajas económicas que representaba. El neoclásico, en efecto, permitió construir con menor inversión y mayor rapidez, ya que la arquitectura grecoromana en la cual está asentado, en su desnudez estructural y simplicidad ornamental, resultó ser más práctica, más "moderna" y fundamentalmente más barata que la barroca.

Los conceptos de democracia, igualdad, libertad, Estado, tan en uso durante el enciclopedismo, entroncaron perfectamente con las aspiraciones de la sociedad novohispana que buscaba la independencia de la metrópoli española. La ilustración sostenía que el hombre era infeliz por su ignorancia e irracionalidad, por lo que el único camino viable para conducirlo a la felicidad era darle "la luz de la razón" por medio de la educación. ${ }^{11}$ Esta educación implicaba, en cuanto a la arquitectura, el conocimiento de fuentes antiguas tales como Vitruvio, $\mathrm{Pa}$ lladio, Vignola, etc., por to que la arquitectura neoclásica hizo uso de repertorios formales griegos, romanos y esquemas renacentistas basados en

popular y rural empleo repertorios formales neoclísicos, esto se hizo hasta finales del siglo, casi al iniciarse el porfiriato, es decir con un retraso considerable, por lo que habra que consignarlas como obras apartadas del neoclásico inicial ya que responden a realidades distintas. Cabe señalar que aunque la Iglesia hizo uso también del neoclásico, parecería ser que lo asumio para congraciarse, primeramente con la corona y después con los gobiernos alternantes, y no necesariamente como una preferencia estilística; esto, evidentemente, habrá de estudiarse más a fondo.

II Álvarez, Santalo, Siglos, 1985, p. 37. aquéllos. Sin embargo era necesario que dichos conocimientos fueran empleados mediante la práctica y observancia de las reglas establecidas por los tratadistas clásicos y renancentistas y con la aplicación de la ciencia y de las sólidas técnicas que la revolución industrial había traído consigo. Se buscó entonces dar un carácter más científico a las artes por lo que los artistas debieron ser "técnicos más que inventores" $\mathrm{e}$ "imitadores más que creadores".12 Este espíritu científico llevó a considerar al arte clásico como un arte progresista, "porque estaba desprovisto de adornos sin sentido y buscaba la perfección de las leyes inmutables sin depender de las im. presiones subjetivas e imperfectas del artista" ${ }^{13}$ Ante tal doctrina, era lógico que todo el arte barroco y específicamente la arquitectura y sus grandes arquitectos, se convirtieran en el blanco de agrios y constantes ataques de numerosas personalidades de la filosofia, el arte y las ciencias. De entre todos éstos, Joachim Winckelmann fue uno de los más radicales; artista al mismo tiempo que teórico erudito, impulsó la investigación "científica e histórica" del arte y ejerció enorme influencia en la estética. Por medio de algunos profesores tales como Velázquez, Tolsá, Ximeno y Fabregat, que venían de las academias de Madrid y Valencia, la atmósfera de repulsión al barroco, asumida en España por Mengs, Ceán Bermúdez, Pons y Azuara, pretendió permearse en el interior de la academia novohispana.

La Real Academia de San Carlos de

12 Brown, Academia, 1976, vol. II, p. 46.

13 Ibid., vol. II, p. 9. 
Nueva España, pretendió ser el conducto por el cual el espíritu empírico de la ilustración europea -sobre el que se estableció el reinado de los Borbones- penetrara a Nueva España y fue, de hecho, la institución que intentó modificar los valores estéticos que habían estado presentes durante los siglos barrocos. Si bien esta tarea de la academia se logró en algunos casos, es obvio también que había varias razones para que, aun con los intentos academicistas, el neoclásico no fuera más que un gusto estético impuesto por las circunstancias y no una elección de la sociedad ahora nacionalista. Sabemos, por ejemplo, que en el Colegio de Mineria, del cual egresaron numerosos ingenieros y arquitectos, ${ }^{14}$ se siguieron una serie de ejercicios en los que se incluían conceptos del barroco anterior; sabemos también que existieron durante todo el XIX talleres independientes de corte colonial y aun de extranjeros que fueron apoyados incluso por diversos gobiernos liberales y conservadores, y que funcionaron al margen de la academia. ${ }^{15}$ Es más, también sabemos cómo incluso para algunos profesores de la academia fue difícil cambiar los esquemas formales y espaciales barrocos por los neoclásicos. ${ }^{16}$ Es obvio entonces que

\footnotetext{
14 Consúltese a Casanova, "1861-1876", p. 119.

is Los talleres extranjeros pertenecieron más frecuentemente a peninsulares, italianos y franceses, por lo menos en la primera etapa de la academia. Falta determinar la presencia de alemanes, belgas, austriacos y de otras nacionalidades en épocas posteriores.

16 Contamos por ejemplo con un proyecto, el del templo del Presidio de Monterrey, en California, que fue enviado por su proyectista Manuel Ruiz en 1792 a la Real Academia para
}

lo que hasta hoy se ha dicho sobre el neoclásico debe ser revisado, pues, querámoslo o no, es real que la Academia de San Carlos no puede ni debe ser tomada como único eje de la producción artística del siglo XIX, pues ya hemos dicho que muchas cosas escaparon a su control. Entre 1821 y 1843 , por ejemplo, la academia perdió la estabilidad que antes tuvo al perder el apoyo económico de la corona y depender del subsidio del gobierno independiente, así como por la muerte de la mayoría de sus directores de las distintas ramas.

Así, la academia en este periodo no puede ser considerada como el centro decisorio sobre la producción plástica, sino que, por parte del patrocinio gubernamental, se desplazó al centro del gobierno durante el imperio o a agencias gubernamentales, como Relaciones Exteriores o el ayuntamiento, mismas que encargaron sus proyectos a talleres independientes, tanto a aquellos de resabio gremial como a los de artistas extranjeros que se establecieron en México después de la independencia. ${ }^{17}$

En el caso del siglo XIx, la Academia ha sido vista siempre como la institución única, sin tomar en cuenta al-

su aprobación, con la corrección que le hiciera nada menos que el director de la propia academia, Antonio González Velázquez. Resulta extraordinariamente curioso cómo, a pesar de ser la fachada de Ruiz totalmente barroca, las correcciones del director de San Carlos se limitan a eliminar unas cuantas molduras y a modificar mínimamente la proporción. Esto de. muestra que no siempre se cuido, como se ha dicho, el seguimiento de las normas academicistas.

${ }^{17}$ Acevedo, "1821-1843", p. 35. 
gunas otras, como el Colegio de Minería, ya citado; de esta manera, se hace necesario estudiar la producción plástica desde otra perspectiva pues, como señala Eloísa Uribe:

Las instituciones permiten rescatar una historia de la producción plástica, auspiciada por los grupos dominantes, y poco revelan sobre la producción de otros grupos, con la naciente cultura de masas, así como el trabajo de los artesanos que siguió subsistiendo [...] Al estudiar la formación de grupos sociales a partir de su injerencia en la producción plástica, es necesario también incluir a las clases subalternas. Hasta el momento no se ha trabajado ninguna fuente que permita conocer la producción de estos grupos. Precisamente el hecho de tratarse de grupos subalternos hace difícil el estudio de su producción, puesto que no tuvieron instituciones o medios para lograr su conservación ni el interés por rescatarla. ${ }^{18}$

En México, durante la etapa colonial, los artistas y arquitectos se formaban en talleres, hasta que en 1785 se fundó la Real Academia de San Carlos de Nueva España. Importa señalar que ésta se fundamentó ampliamente en las academias existentes en la península, principalmente en la de San Fernando, de Madrid, fundada en 1752, y la de San Carlos, de Valencia, erigida en 1753. Al principio la academia novohispana no contó con profesores suficientes ni con un lugar propio, por lo que comenzó a funcionar en un local de la Casa de Moneda, hasta que en 1789 se traslado al anti-

18 Uribe, "Introducción general", p. 11. guo Hospital del Amor de Dios. Hacia 1791 comenzaron a llegar los profe. sores, siendo director general Antonio González Velázquez, quien fungió asimismo como director de arquitectura; Manuel Tolsá ocupó el cargo de director de escultura y Rafael Ximeno y Planes, de pintura. A partir de esas fechas la academia estableció nuevas pautas para el desarrollo de las artes de Nueva España, pautas que, como hemos visto, no siempre fueron seguidas. En cuanto a la arquitectura, por ejemplo, se intentó someter a los maestros de arquitectura de la ciudad de México y de las provincias a construir sólo aquello que era aprobado por la academia; para este efecto se emitió un decreto el 28 de octubre de 1792 en donde la Junta de Policía ordenaba que se pidiera a la academia aprobación para la erección de cualquier obra a partir de esa fecha. ${ }^{19} \mathrm{Mu}$ chos fueron los maestros que solicitaron ante la Real Academia el título de académicos de mérito para poder ejercer su oficio, aunque sujetos a la aprobación o rechazo de sus proyectos por dicha institución. José Damián Ortiz de Castro, Francisco Guerrero y Torres, Ignacio Castera, José Buitrón y muchos más solicitaron ante la academia dicho título. El procedimiento que se seguía era generalmente el siguiente: junto a la solicitud se anexaba un proyecto realizado por el solicitante, que incluía plantas, cortes y alzados; era necesario anexar también documentos que comprobaran el origen familiar y racial del aspirante y,

19 Archivo Histórico de la Academia de San Carlos (AHASC), documento 725, gaveta 7 (1792). 
en muchos casos, se completaba el expediente con alguna o algunas cartas de recomendación de otros académicos de mérito ya aceptados o de antiguos clientes del solicitante. Es interesante señalar que la aprobación de los proyectos por construir dependía en gran medida del estilo del proyecto presentado. Así, era común que los que seguian esquemas claramente barrocos fueran rechazados, buscándose con esto que la academia fungiera como celosa vigilante para que el neoclásico "de buen gusto y noble simplicidad" se impusiera en lugar del "feo, confuso y arbitrario barroco". Resulta curioso mencionar que muchos arquitectos, defensores aún del barroco, llegaron a hacer un doble proyecto, uno en estilo barroco y otro, que era el que enviaban a San Carlos para su aprobación, en estilo neoclásico, construyendo obviamente el primero. Múltiples fueron las denuncias y llamadas de atención a Ig. nacio Castera, por ejemplo, quien con frecuencia recurrio a este método para imponer su creatividad por sobre los dictámenes de la real institución.

La Real Academia fungió como transmisora, a ciertos grupos, de los conceptos en contra del barroco y a favor del neoclásico, y de diversos tratados clásicos y renacentistas de las "tres nobles artes", así como de obras de carácter técnico y científico que racionalizaban la práctica y ejecución de las artes. Muestra de esto es el inventario de la biblioteca de San Carlos que se efectuó en 1791; en él se cosignan 49 libros, dentro de los cuales se incluyen: el Compendio de matemáticas de Benito Bails, un volumen de la Geometría de Euclides, varios tomos de arquitectura italiana y el Vitruvio; en
1792 se pidieron a Madrid 30 libros, entre los cuales se incluían varios de Winckelmann, el Vignola y otros libros científicos del mismo Bails. ${ }^{20}$

Esta época (1785-1821) ha sido manejada por diversos autores como la primera etapa de la Real Academia y es sin duda, hasta el momento, la que se considera más importante bajo el punto de vista de la producción arquitectónica neoclásica. Importa destacar también que en ella fue determinante la influencia que las academias penin. sulares ejercieron sobre la novohispana de San Carlos. En 1821, por falta de presupuesto y por diversos problemas originados por la guerra de Independencia, fue cerrada brevemente. ${ }^{21}$ Falta por estudiarse la producción arquitectónica hecha por mexicanos al margen de la institución, y aun la obra neoclásica menor salida de la Academia, ya que de hecho la consignada hasta ahora se refiere a las obras más significativas.

Respecto a lo formal, durante esta "primera etapa" los proyectos se apo. yaron ampliamente en los esquemas clásicos griegos y romanos, y muchos de los alumnos de los primeros profesores academicistas siguieron construyendo bajo estos patrones; algunos hubo también que se apegaron más a cánones renacentistas. El orden colosal, la organización espacial centralizada, el remarcamiento de los sillares en hiladas horizontales, el ritmo alterno de frontones curvos y triangu-

${ }^{20}$ Brown, Academia, 1976, p. 15. Consúltense también AHASC, documentos 638 (1791) y 822 (1794), gaveta 5.

21 Consúltese a Ramírez, "Arte", 1986, en donde señala las etapas en que se ha llegado a dividir la historia de la Academia. 
lares sostenidos por ménsulas, el uso de elementos tan queridos por Palladio como las placas lisas coronando vanos, y los vanos acodados como los que diseñó para el palacio Valmarana, fueron recursos muy manidos. Arquitectos hubo también, como ya mencionamos, que en fachadas, plantas e interiores emplearon ciertos elementos y esquemas francamente barrocos. Tresguerras, por citar alguno, en el templo del Carmen de Celaya, desarrolló una fachada principal en la cual el eje compositivo centralizado se evidencia por su esbelta y única torre que descansa sobre el nártex porticado y rematado por un frontón triangular. Este esquema, como sabemos, fue reiteradamente utilizado en el barroco inglés, que originó después el "neopalladionismo" y que llevó, años más tarde, al neoclasicismo; recorde. mos por ejemplo las fachadas de St. Mary-le Strand, la de St. Martin inthe Fields y principalmente la de St. Bride en Londres, en donde la torre, al igual que la del Carmen, está flan. queada por sendas ménsulas terminadas en róleos, elemento usado desde el barroco colonial y que pervivió en el neoclásico.

Como ya se dijo, muchas otras obras y edificios menores fueron construidos durante esa primera etapa; algunas poco conocidas y otras francamente ignoradas permanecen en diversos archivos en espera de ser estudiadas. Ejemplos de esto son los proyectos ya citados de José Mariano Orihuela para los arcos de la Alameda de Querétaro, la casa mesón con temazcal de Mariano Falcón (1810), el proyecto para el templo de San Juan Bautista Culhuacán, de José Buitrón
Velasco (1803), el templo de Nuestra Señora de la Concepción de Santonio de Santa María Incháurregui en Cosamaloapan (1806), el del Señor Crucificado de Otatitlán de Francisco de los Reyes (1805) y un proyecto de mercado para la esquina de los Santos, en la ciudad de México, de Ignacio Serrano. 22 Si bien no hubo una movilidad constructiva significativa, hubo proyectos tan importantes como el presentado por Tadeo Ortiz en su obra México considerado como nación independiente y libre, de 1831, en la cual

hace una serie de planteamientos acerca del tipo de urbanización y arquitectura que se debía proyectar en la ciudad de México [...] Ortiz decía que todos los objetos de embellecimiento tienen una amplia relación y deben estar en armonía con los de salubridad; tenía una preocupación por arbolar las avenidas y proponía la idea de dotar a la ciudad de grandes puertas triunfales adomadas con estatuas de héroes y alegorías. En cuanto a las plazas criticaba las formas abigarradas y edificios de mal gusto [...] Proponía eliminar de la plaza Mayor el Parián y el Seminario, al tiempo de construir fachadas a los edificios que la rodean, como modelos de los cuatro órdenes de la arquitectura. ${ }^{23}$

Para la mayoría de los autores que escriben sobre la arquitectura del XIX, la segunda etapa de la academia comienza con la dictadura del general

22 Además de estos proyectos, hemos localizado tambien algunos igualmente significativos en distintos ramos del AGN.

23 Acevedo, “1821-1843", p. 52. 
Santa Anna, quien a instancias de don Juan Echeverría se comprometió, por medio de un decreto de 1843 , a restituir la dignidad e importancia que dicha institución merecía. En él se marcaban las pautas a seguir para la reapertura de la academia. ${ }^{24}$ En 1846 llegaron los primeros maestros extranjeros: Pelegrín Clavé, que fungió como director de pintura, y Manuel Vilar, que se encargó de la escultura. En 1847 se iniciaron las clases solemnemente y a partir de ese momento comenzaron a llegar nuevos maestros para completar la planta de profeso. res. Así, en 1845 Eugenio Landesio llegó para impartir las clases de paisaje, y en 1856 el arquitecto italiano Javier Cavallari se incorporó para encargarse de la enseñanza de la arquitectura. Antes de que San Carlos fuera reestructurado y reinaugurado, eran profesores de arquitectura Francisco Hermosa, Joaquín Mier y Terán, Vicente Heredia, José María Regó y Manuel Delgado; y entre sus discípulos más sobresalientes se encontraban Ventura Alcacérreca, Manuel Rincón y Miranda, Ramón Rodríguez Arangoity -quien intervino posteriormente durante el imperio de Maximiliano en la aplicación y remodelación del Castillo de Chapultepec-, Ramón y Juan Agea y Francisco Somera. ${ }^{25}$

Sin embargo, un alto porcentaje de la obra producida por ellos ha sido destruida, por lo cual hasta la fecha no ha sido posible tener una imagen más clara y más precisa de su pro-

24 Los artículos de este decreto pueden consultarse en Fernández, Arte, 1967, p. 41.

25 Ibid., p. 118. ducción. Igualmente, para esta etapa se menciona, en la bibliografía existente, la obra de arquitectos extranjeros y de sus discípulos más cercanos, y sólo de aquellos egresados o relacionados con la academia. Esto nos lleva a la necesidad de incluir en el estudio de la arquitectura del XIX un sinnúmero de proyectos que se pueden localizar fundamentalmente en el Archivo General de la Nación, en el Archivo de la Academia de San Carlos y en varios más. Para esta etapa, por ejemplo, ingenieros egresados del Colegio Militar intervinieron en muchos proyectos urbanos; asimismo, como señala Eloísa Uribe: "En los años cuarenta y cincuenta, la práctica realizada en los talleres independientes fue tan importante como la que se realizó dentro de la academia."26

De los arquitectos de esta "segunda etapa", el español Lorenzo de la Hidalga (1810-1872) fue sobresaliente y trabajó, tanto bajo la dictadura de Santa Anna como para Maximiliano. De la Hidalga se tituló en la Real Academia de San Fernando de Madirid en 1836 y pasó después a París, en clonde fue discípulo de Labrouste y Violletle-Duc durante dos años, al fin de los cuales vino a México. ${ }^{27}$ Otro arquitecto que cabe mencionar es Javier Cavallari que, como dijimos antes, fue el encargado de la enseñanza de la arquitectura en esa etapa. Su trayectoria como arquitecto y profesor fue larga e importante; estudió en Alemania, trabajó como arqueólogo en Italia e hizo una serie de planos de ciudades

26 Uribe, "1843-1860", p. 73.

27 Fernández, Arte, 1967, p. 118. 
y edificios en dibujos y grabados, publicando además una Historia de las artes y una Historia de la arquitectura. Al venir a México abandonó su puesto de director de la Academia de Milán. Aquí reestructuró los planes de estudio, uniendo la carrera de arquitecto con la de ingeniero civil. ${ }^{28}$ Fueron sus discípulos Lorenzo de la Hidalga, Manuel F. Álvarez, Antonio Torres Torija, Antonio M. Anza y Mariano Soto. Aunque abandonó el país en 1864, es seguro que sus enseñanzas habían ofrecido a sus alumnos un criterio más amplio y más abierto y sin prejuicios estéticos que les permitieron una mayor comprensión y respeto hacia los diferentes estilos o lenguajes desarrollados por las culturas occidentales y orientales, actitudes tan necesarias para el posterior eclecticismo. Fue por esto que algunos de sus alumnos, durante el porfirismo, desarrollaron una arquitectura ecléctica que, parece, fluyó casi espontáneamente sin rupturas tajantes a partir de los ideales de la arquitectura romántica, que fue vistiendo de ornamentación, poco a poco, al "frío" neoclásico, tan ajeno a la complejidad formal que el ser novohispano había demostrado disfrutar durante los siglos barrocos y que constituye tal vez uno de los rasgos de identidad del mexicano.

A lo largo de este periodo se construyeron teatros, cafés, asilos, mercados, escuelas, hospitales, cementerios, cárceles, templos y escasas fábricas; se reconstruyeron iglesias y conventos que la guerra de Independencia había destruido y se terminaron aque-

${ }^{28}$ Ibid., p. 120 llas obras que habían sido interrumpidas por la misma. Si bien muchos de estos edificios fueron sólo adaptaciones de espacios construidos con anterioridad, casi todos se remozaron siguiendo esquemas formales neoclásicos. Para una época de tanta inesta. bilidad, los edificios que hoy catalogamos como de "recreación", cubrie. ron una importante función como catalizadores del descontento social y económico de la capital y del país. En cuanto a los teatros, por ejemplo, el "provisional" o Teatro de los Ga. llos, el Principal, el de Vergara, el Coliseo Viejo o el de Nuevo México, el Gran Teatro Nacional también llamado de Santa Anna, inaugurado en 1844, fueron altamente frecuentados por todos los estratos socioeconómicos de la ciudad, y el gobierno se encargó de contratar a compañías de teatro francesas, italianas y españolas para que actuaran en ellos. El establecimiento de cafés, en donde se reunían estratos sociales diversos, caracterizó asimismo a la época. La Bella Unión funcionaba igualmente como salón de baile, el Café del Sur, que se localizaba en el portal de los agustinos, reunía en su interior a la milicia de bajo grado, tahúres y burócratas de escasa jerarquía; el llamado La Gran Sociedad, en cambio, como queda dicho con su nombre, era frecuentado por la elite; otros, como el Veroli, el del Progreso y El Cazador, gozaban de un menor prestigio. ${ }^{29} \mathrm{~A}$ pesar de los datos anteriores, si comparamos ia escasa producción arquitectónica de la

29 García Ruiz, "Aspectos", 1986, t. 12, p. 2082. 
primera etapa con la producida durante la segunda, es notable la aún más escasa y menos relevante arquitectura de este segundo periodo. No debemos dar por hecho, sin embargo, que tal situación haya sido real hasta que no hurguemos más profundamente en las fuentes de la época. El taller del francés Enrique Griffon y el del hispano Lorenzo de la Hidalga, por ejemplo, contribuyeron a la transformación de la ciudad de México con innumerables obras; pocas son sin embargo las que han sido estudiadas. ${ }^{30}$

Si bien las continuas guerras internas y externas que sufría el país modificaron necesariamente las actividades de sus pobladores, ${ }^{31}$ no podemos afirmar totalmente que por esta razón no había actividad constructiva; la expe. riencia contemporánea demuestra hoy que se construye mucho más de lo que se consigna en los censos delegacionales; con mayor razón debió suceder en aquella época, cuando el control, como hemos visto ya, no podía ser tocalmente eficaz.

En los párrafos anteriores hemos señalado algunos puntos que nos parece necesario analizar con mayor cuidado para crear una imagen global de la arquitectura del XIX. Falta también, evidentemente, un análisis más deta-

${ }^{30}$ Katzman, Arquitectura, 1973, p. 280.

31 Para mediados del siglo $\mathrm{xIx}$, México contaba con 65178 empleados en distintos ramos de la milicia; 13545 se dedicaban a la burocracia; 1816238 trabajaban como jornaleros; 294325 eran criados; 268984 se dedicaban a la labranza; 146174 eran comerciantes; había 896 músicos, 106 actores líricos y dramáticos y sólo 14 arquitectos y 9 ingenieros civiles. Véase García Ruiz, "Aspectos", 1986, vol. 12, p. 2083. llado de las décadas posteriores al gobierno del general Santa Anna. Es obvio que tanto las leyes de desamortización (1850) como las de nacionalización de los bienes eclesiásticos (1859-61), significaron enormes cambios para la arquitectura y el urbanismo del siglo $\mathrm{xIX}$, y cuyas consecuencias no han sido suficientemente estudiadas. No fueron menores los cambios y los proyectos realizados durante el imperio de Maximiliano, quien además era un resuelto aficionado a la arquitectura. En su gobierno, no sólo se proyectaron múltiples edificios, sino que incluso se elaboraron proyectos urbanísticos y una gran cantidad de obras públicas; asi, por ejemplo, se inició el paseo del Emperador (paseo de la Reforma), que cobró fuerza hasta el porfirismo, y se elaboró un proyecto que pretendía ampliar la calle de Plateros (hoy Madero) hasta la plaza Mayor, en la cual el edificio del Sagrario sería removido y reconstruido en otro lugar para dejar aislada en su magnificencia a la catedral metropolitana. ${ }^{32}$ El gusto de Maximiliano por la arquitectura se re. flejó en el interés que mostró la Real Academia, en su exposición de 1865 , en exhibir dibujos de sus alumnos que representaban hoteles, palacios municipales, puentes, museos, catedrales y estudios de los órdenes clásicos, y de edificios góticos y románicos, que evidenciaban ya ideas historicistas. Al respecto cabe mencionar que ya desde el segundo imperio se inició un in. terés por lo prehispánico, hecho que ha sido señalado por Xavier Moyssen,

32 Véase Álvarez, Cavallari, 1906, p. 119. 


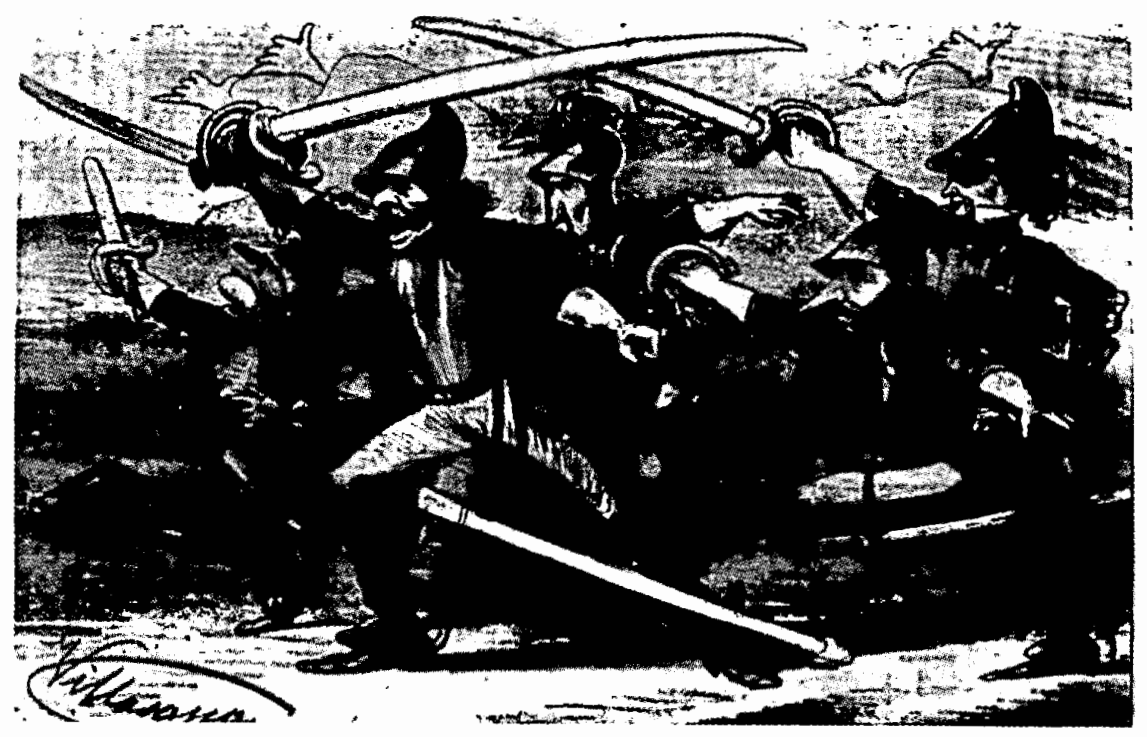

quien destaca que fueron encargados al pintor Eugenio Landesio una serie de frescos con temas prehispánicos para decorar el Castillo de Chapultepec, proyecto que por desgracia no llegó a realizarse debido a la caída del imperio. ${ }^{33}$ Todo esto está por estu. diarse y habrá que hacerlo.

Un último punto que quisiéramos hacer notar es que la bibliografia existente sobre el siglo XIX ha concebido al periodo de una manera fragmentaria y ha sido incapaz de percibir en él, y por tanto de describir, la secuencia histórica que une a unas etapas con otras y que les da sentido. Sólo desde esta perspectiva podrá advertirse que el proceso del xix es el gestador de una

33 Consúltese Moyssen, "Eugenio", 1963, p. 72. actitud y una disposición mental totalmente abierta que permitieron, posteriormente, la plena aceptación de las formas, las soluciones y la pluralidad temática que abarcaba el eclecticismo. Esa estimación fragmentaria, creemos, ha impedido entender cuál fue la evolución no sólo de la arquitectura, sino aun de otras artes. En el siglo XIx, el neoclásico aparece siempre como un estilo impuesto, y es real que una gran parte de la sociedad, en diferentes momentos, lo vivió así. Los criollos, al. tamente poderosos hacia finales del XVIII, lo vivieron como una nueva imposición de los Borbones; los peninsu. lares, en cambio, lo entendieron como la incorporación de Nueva España a la ilustración; las castas formadas por el pueblo llano no tuvieron, como siem- 
pre, ni voz ni voto, y se movieron apartadas de las connotaciones intelectuales y de la novedad estética del neoclásico.

Es posible entonces que a lo largo del XIX la sociedad ahora mexicana haya interiorizado y mantenido en estado latente el conflicto que parecería existir entre su gusto ancestral por la complejidad ornamental y la carencia de un estilo que continuara esa tradición de complejidad formal. El barroco le estaba vedado por su asociación con la etapa colonial, la cual se quería enterrar después de la guerra de Independencia; el neoclásico, por su parte, le era ajeno, tanto porque también fue impuesto al final de la colonia, como porque después estuvo asociado a los alternantes grupos en el poder, liberales o conservadores, con toda la confusa carga ideológico-política que la alternancia significó, además de que -como señalamos antes- este estilo, a pesar de lo económico que resultaba en comparación con el barroco, no poseía la riqueza formal que el mexicano estaba acostumbrado a manejar. Desde esta perspectiva, es posible que el gusto que la sociedad porfiriana mostró por el eclecticismo de la época pueda entenderse no nada más como producto de la xenofilia, sino también como el producto de aquella interiorización a la que aludimos antes; el eclecticismo arquitectónico devolvía al mexicano la posibilidad de enriquecer formalmente, una vez más, su lenguaje arquitectónico; más aún, el eclecticismo permitió al mexicano hacer uso de repertorios tanto prehispánicos como coloniales, exentos de sus anteriores connotaciones políticas y ubicados ahora en contextos más universales, y tan válidos como los de los repertorios góticos, románticos o renacentistas. ${ }^{34}$

Es este particular siglo el que puede tal vez explicar muchos de los procesos de la arquitectura porfiriana y aun de la posterior nacionalista y de otras etapas subsiguientes. Por lo pronto vemos en el xIX, como dijimos al principio, un gran salto, una gran laguna de conocimientos y de explicaciones entre el neoclásico y el eclecticismo, lo cual en la historia nunca se da; siem. pre lo surgido como novedad -en este caso el eclecticismo- está fundamentado amplia y firmemente en el pasado; este pasado es el que trataremos de rescatar y explicar en una futura investigación.

\section{BIBLIOGRAFA}

-Acevedo, Esther, "1821-1843", en Y todo... por una nación. Historia social de la pro. ducción plástica de la ciudad de México, 1761-1910, s. p. i.

-Álvarez, Manuel G., El Dr. Cavallart y la carrera de ingeniero civil en México, A. Carranza y Comp. Impresores, México, 1906.

34 Es frecuente, cuando se habla de la arquitectura porfiriana, mencionar al neoindigenismo y otros "neos" europeos y no dar importancia o pero aún no querer ver -tal vez por algún resabio winckelmanniano o por un antihispanismo arquitectónico- que también se dio el neocolonial, aunque en menor escala y ya empezado el siglo. En este sentido vale la pena consultar Katzman, Avquitectura, 1973, pp. $50,80,89$, en donde menciona algunos ejemplos tales como la fachada de la Universidad Nacional (1906-11) y el Anfiteatro Bolívar de Samuel Chávez, la transformación del Ayuntamiento hecha por Manuel Gorozpe (1906) y un proyecto para la casa ubicada en Sur 14 de Nicolás Mariscal. 
-Álvarez Santaló, León Carlos, Los siglos de la bistoria, Salvat, Barcelona, 1985 (Aula Abierta Salvat-Temas Clave, 34).

-Báez Macías, Eduardo, Guía del Archivo de la Antigua Academia de San Carlos. 1821-1843, Universidad Nacional Autónoma de México, México, 1972.

-Brown, Thomas A., La Academia de San Carlos de la Nueva España, 2 vols., Secretaria de Educación Pública, México, 1976 (Sepsetentas, 300).

-Casanova, Rosa, "1861-1876", en $Y$ todo... por una nación. Historia social de la producción plástica de la ciudad de México, 1761-1910, s. p. i.

-Fernández, Justino, El arte del siglo $x D x$ en México, Universidad Nacional Autónoma de México, México, 1967.

-García Ruiz, Alfonso, "Aspectos sociales y económicos de la reforma y la república restaurada", en Historia de México, vol. 12, Secretaría de Educación Pública/Salvat, México, 1986.

-Katzman, Israel, Arquitectura del siglo $X I X$ en México, Universidad Nacional Autónoma de México, México, 1973.

-Lira, Andrés, Comunidades indígenas frente a la ciudad de México, Tenochtitlany Tlatelolco, sus pueblosy sus barrios,
1812-1919, El Colegio de México/El Colegio de Michoacán/Conacyt, México, 1983.

-Lombardo de Ruiz, Sonia, "Las reformas borbónicas y su influencia en el arte de la Nueva España", en Historia del arte mexicano. Arte del siglo XIX, vol. 9, Secretaría de Educación Pública/Salvat, México, 1986.

La Ciudadela, ideología y estilo en la arquitectura del siglo XVII, Universidad Nacional Autónoma de México, México, 1980.

-Morales, María Dolores, "Estructura urbana y distribución de la propiedad en la ciudad de México en 1813", Historia Mexicana, vol. xxv, núm. 3 (99), eneromarzo 1976.

-Moyssen, Xavier, "Eugenio Landesio, teórico y crítico de arte", Anales del Instituto de Investigaciones Estéticas, suplemento 8 (31), 1963.

-Ramírez, Fausto, "El arte del siglo XIX", en Historia del arte mexicano. Arte del siglo $X X X$, vol. 9, Secretaría de Educación Pública/Salvat, México, 1986.

-Uribe, Eloísa, "Introducción general", en $Y$ todo... por una nación. Historia social de la producción plástica de la ciudad de México, 1761-1910, s. p. i. 